\title{
Consistent Controls on Trace Metal Micronutrient Speciation in Wetland Soils and Stream Sediments
}

J.G. CATALANO ${ }^{1 *}$, J. YAN ${ }^{1}$, E.D. FLYNN ${ }^{1}$, N. SHARMA ${ }^{1}$, D.E. GIAMMAR ${ }^{1}$, G.E. SCHWARTZ ${ }^{2}$, S.C. BROOKS ${ }^{2}$, P.B. WEISENHORN $^{4}$, K.M. KEMNER ${ }^{4}$, E.J. O'LOUGHLIN ${ }^{4}$, D.I. KAPLAN $^{5}$

${ }^{1}$ Washington Univ., St. Louis, MO 63130, USA

(*correspondence: catalano@wustl.ed)

${ }^{2}$ Oak Ridge National Lab., Oak Ridge, TN 37831, USA

${ }^{3}$ Argonne National Lab., Argonne, IL 60439, USA

${ }^{4}$ Savannah River National Lab., Aiken, SC 29808, USA

Trace metals in microbial enzymatic systems drive diverse biogeochemical processes. Past studies demonstrate that low trace metal availability inhibits methanogenesis, denitrification, and $\mathrm{Hg}$ methylation in pure culture. However, it is unclear whether such limitations manifest in natural systems. If present, trace metal speciation likely controls these limitations as it directly impacts bioavailability.

The abundance and speciation of the bioessential metals $\mathrm{Cu}, \mathrm{Ni}$, and $\mathrm{Zn}$ have been characterized in three natural aquatic systems. Soils and sediments were collected from marsh wetlands located at Argonne National Laboratory, riparian wetlands in the Tims Branch watershed at the Savannah River Site, and the stream bed of East Fork Poplar Creek at Oak Ridge National Laboratory. Total solid phase trace metals in the marsh wetlands, one riparian wetland site, and the stream bed showed weak correlation with $\mathrm{Fe}, \mathrm{S}$, or $\mathrm{Mn}\left(\mathrm{R}^{2}<0.2\right)$. In contrast, a second riparian wetland site displayed strong correlation between trace metal abundances in soil and the Fe, $\mathrm{S}$, and Mn contents $\left(\mathrm{R}^{2}=0.80\right.$ to 0.95$)$.

Despite these distinct patterns of element associations, the speciation of $\mathrm{Cu}, \mathrm{Ni}$, and $\mathrm{Zn}$ (as determined by XAFS spectroscopy) varied little among the field sites. $\mathrm{Cu}$ primarily occurred as a sulfide species (60-90\%) at all sites, with the remaining adsorbed to organic matter and minerals. $\mathrm{Ni}$ and $\mathrm{Zn}$ also both displayed consistent speciation across the field sites, with $20-40 \%$ occurring as a sulfide species and the remainder associated with phyllosilicates and organic matter. Trace metals also showed similar relative extractability among all sites studied. This consistent speciation across diverse aquatic systems suggests that trace metal availability has surprisingly uniform controls. Reduced sulfur played a ubiquitous role in binding trace metals despite more than an order of magnitude variation in sulfur abundance, and no trends in speciation versus $\mathrm{Fe}$ or Mn content are apparent. Variations in bulk composition are thus likely not indicative of distinct trace metal availabilities in aquatic systems. 